\title{
Critical Success Factors for Public Private Partnerships in the UAE Construction Industry- A Comparative Analysis between the UAE and the UK
}

\author{
Khalid Almarri ${ }^{1}$ and Bassam Abu-Hijleh ${ }^{2}$ \\ ${ }^{1}$ Assistant Professor, Faculty of Engineering and IT, the British University in Dubai, P.O. Box 345015, Dubai \\ International Academic City, Dubai, United Arab Emirates, E-mail: khalid.almarri@buid.ac.ae (corresponding author). \\ ${ }^{2}$ Professor, Faculty of Engineering and IT, the British University in Dubai, P.O. Box 345015, Dubai International \\ Academic City, Dubai, United Arab Emirates, E-mail: bassam.abuhijleh@buid.ac.ae
}

Project Management

Received July 18, 2016; received revisions November 6, 2016; November 13, 2016; November 15, 2016; accepted November 15,2016 Available online December 6, 2016

\begin{abstract}
Procurement instruments by Public Private Partnerships (PPP) have shown their amazing capacity in procuring public works from around the globe. Their success rate has been immense as they are known to bring efficiency, quality, innovation, experience, funds, and most importantly, the art of risk sharing to developed projects.

This research aims to pinpoint the critical success factors (CSFs) that are needed to implement PPPs in transitional economies. We have taken UAE as a case study and will be comparing its results with that of the UK's; a developed country. Relevant data was collected through a questionnaire to establish the PPP critical success factors for the each of the two countries. In this questionnaire, data was collected from 30 participants residing in the UAE and 62 participants residing in the UK. A comparative analysis between the results of the UK and UAE showed a great deal of similarity between the two in PPP practice trends in the critical success factors. Both countries ranked the same nine factors as the most significant ones out of the eighteen critical success factors for implementing PPPs. These factors were commitment of public and private parties, appropriate risk allocation, committed and competent public agency, transparent procurement process, strong private consortium, competitive procurement process, political support, detailed cost/benefits assessment, and good governance. Whereas, the major differences were related to local financial market, macro-economic conditions, and favourable legal framework.
\end{abstract}

The findings were validated through a small sample of practitioners using the Partnering Performance Index, and were found to be comprehensive, objective, reliable, practical, replicable, and adaptable.

Keywords: Public procurement, PPP, critical success factors, construction.

\section{Introduction}

PPPs are known for their high success rates in terms of efficiency, innovation, quality, funding, risk sharing to developed projects, as well as experience (Alfen, 2010). Thus, PPP have become an extremely popular mechanism for procuring public work around the globe (Alfen, 2010; Roumboutsos and Saussier, 2014). The PPP terminology was first introduced in the UK in 1997 by the labour government. Prior to this, other arrangements of similar collaborative form of engaging the private sector fell within the private finance initiative (PFI), which was introduced by the conservative government in 1992 (Broadbent and Laughlin, 2003, 2004). Since this engagement form was introduced, four main types of PPPs have emerged. These are BOO (build own operate), BOT (build operate transfer), DBFO (design build finance operate), and BOOT (build own operate transfer). The most widely used of these is BOT (Osei-Kyei and Chan, 2015).

Gupta and others (2013) declare that all processes have different success factors. These factors are extremely important according to the context of different projects. Their ranking is important in order to perform well and achieve the objectives of an organisation in a successful manner. Rockart and the Sloan School of Management developed the concept of Critical Success Factors (CSF) and developed the terms in relation to project management and the application of information systems (Jefferies, Gameson and Rowlinson, 2002, p.354). The critical success factors are classified by Rockart as belonging to different niches, such as the environment, strategy and specific industry. Some elements also belong to the temporal group. The environmental factors include economy and infrastructure. The strategic factor describes 
the objectives of a business. The temporal factors are the ones that discuss elements such as barriers and internal resistance elements within a business (Jefferies et al., 2002). According to different literary sources, the concept of critical success factors describes areas where positive results are essential for companies to achieve success for stakeholders. Rockart, in fact, especially described these factors for situations that demand public-private partnerships (Jefferies et al., 2002).

According to Yang and others, there is a need to research the effects of CSFs, especially in economies which are transitioning in unstable environments. There are a number of public private partnership (PPP) studies, but the need is to especially discuss environments that are undeveloped and are not controlled by strong institutions (Yang et al., 2013). There are many local problems that need to be considered when researching different PPP environments. Elements such as good governance and transparency are usually important when looking at the complexities faced by businesses. The political situations in the region as well as the working of strong institutions are important in this regard. The financial aspect of the local markets is also important (Dulaimi et al., 2010). The number of studies which describes PPP in transitional economies, such as the UAE is really limited and therefore, there is a great need to carry them out just like they are available for developed countries. This problem requires an inquire using quantitative analysis of different market environments including both transitional and developed economies (Yang et al., 2013).

The new PPP law, enacted in Dubai in 2015, aimed to encourage the private sector to bridge the financial deficit in developing the large-scale projects due to the declining oil prices (The National, 2016). This law will encourage more investors to seek partnerships with the government. Currently, the plans for PPPs in the UAE include the US\$8 billion renewable energy project that was announced by Dubai electricity and water authority earlier this year, and the US\$32 billion expansion at Al Maktoum airport (The National, 2016). According to an estimate, there were singular digit PPP projects in the UAE before 2010. There has been no credible work for developing partnership projects in the UAE in the public-private sector (Dulaimi et al., 2010). As there are different conditions and factors present in different countries, it is essential to perform individual studies on CSFs in these countries. The main characteristics of PPP keep changing and usually depend on the government incentives and the amount of risk involved in a particular project (Dada, 2012). The purpose of this study therefore, is to cover the gap which is present in the terms of research of CSFs in countries such as UAE. As Yang et al. (2013) specifically stated that, "PPPs are relatively new in transitional countries, few frameworks have been proposed." This shows that there is a particular need for finding important factors that affect PPP. The study aims to answer this inquiry:

What are the critical success factors that affect publicprivate partnerships especially in the construction industry of UAE and how can these factors be integrated properly to develop a PPP model for specific use in the country?

\subsection{Public Private Partnerships}

PPPs are expected to help in maximizing benefits that are needed in the development of projects since "PPPs involve the private sector and are long term relationships with them in providing public services that in many cases had previously been the responsibility of the public sector"(Broadbent and Laughlin, 2004, p.4). Successful utilization of PPP contracts in developed countries, including the United Kingdom, has set the example for transitional economies to follow suit in procuring governmental projects. The advantages for this model in terms of risk transfer and accessing private funds are well documented. These advantages are also attractive to less privileged countries when seeking international PPP contracts. PPP contracts involve risk sharing, quality, efficiency, innovation, private sector funds as well as experience (Osei-Kyei and Chan, 2015).

The advantages of PPPs are so pronounced that different governmental agencies have started using this method to provide services and develop infrastructure. In some developed countries like the United Kingdom, procured governmental projects through the PFI/PPP models have risen to 728 projects in 2014 with a total current value of $£ 56.6$ billion, out of $£ 242$ billion spent on procurement of goods and services that year (HMT, 2014). The Treasury of New South Wales, Australia, has stated that PPPs "are one of the options the Government uses to offer opportunities and procure infrastructure so that better value for money can be offered and services can be improved. This is primarily done through appropriate risk transfer, encouraging innovation, greater asset utilisation and integrated whole-of-life asset management"(NSW, 2012, p.1).

The key characteristic leading to the proliferation of the method was transferring of the project development cycle. This consisted of funding, planning, constructing, managing, and maintaining the projects by private investors who are expected to run them in a better manner and for a specified period of time only (Almarri and Blackwell, 2014; Broadbent and Laughlin, 2003; EU, 2003). PPPs are primarily comprised of concessions or private finance initiatives. The government sets the criteria for investors in order to control the private finance initiative (PFI) payments. The criteria usually include some particular performance targets as well as the availability of the infrastructure. In concessions, there are user collected paybacks (Broadbent and Laughlin, 2003, 2004; EU, 2003; PPPC, 2011).

Achieving value for money in PPP depends on the ability to allocate and identify risks to the parties that have the ability to manage them in a better manner. Risk allocation involves deciding which party will be bearing the financial consequences of variations in the outcome of the project in response to each risk factor. Successful risk allocation will improve value for money in PPP projects. The underlying principle of risk allocation is that each risk should be allocated to the party that can manage it in the best manner possible. This will include allocating risk to the party who is able to control its occurrence, control its impact on the project, as well as absorb its consequences with the lowest financial impact (Chou et al., 2012; WBI, 2012).

In order for PPPs to deliver their expected benefits, their success criteria must be satisfied. It is however important that we highlight and investigate the challenges that are faced during the implementation of PPPs so that their outcomes can be improved. This will also enable governments to sustain their development initiatives. 


\subsection{Traditional and PPP Procurement of Public Projects}

The government awards construction projects in four different ways. The basic method is to only offer a project for either designing or building. The second category describes the combination of first designing and then building. The third category adds financing to the previously mentioned tasks. The fourth category offers the complete model where operation of the building is also offered within the project. The private sector companies usually like to work according to the forth category which is just like going through a PPP model of contract. The first three categories are usually procured using the traditional methods while the fourth one often requires the creation of a complex consortium (EU, 2003; Hoppe and Schmitz, 2013; PPPC, 2011).

The government is the controlling factor in all projects whether they are given through a partnership or through regular procurement. The government directly calls for private parties to apply for a project when using the traditional mode. On the other hand, for a PPP based project, the government declares a set of related specifications as well as the specified timelines for the different phases of the complete project. These specifications describe the period of operation as well as the details of designing and maintenance requirements (EU, 2003; PPPC, 2011).

There are three important elements that describe the PPP model of work. They include finding the funding for the project, then creating ownership and internal control of the project. Funding refers to describing the finances that will be arranged by each partner. Ownership refers to the actual gearing ratio of the project. Internal control describes the managerial procedures for performing in the project. There are different models that are available in PPP such as a management contract and BOT (Build, Operate and Transfer) models. Some others include service contracts, privatisation and agency management (UOM, 2012).

\subsection{Obstacles Hindering the Full Potential of PPPs}

There are many failures such as capital and technological problems that degrade the performance of PPPs. These partnerships can often suffer from behaviour problems because the project opportunity is often partially described, which means that working behaviours have to be modified within the timeline of the project. Mutual trust issues also produce these problems. The public party in a contract aims to look for better guarantees and well defined financial demands that cause problems, when executing the different terms of the contract (Parker, 2009). Policy failures on the other hand are a result of implementing measures without political and authoritarian support. Capital failures are a result of the failure of private funding to keep up with the public funding in an expanding project. This happens when it is difficult for private companies to find capital for investing in ongoing projects. The lack of maturity in the market of PPPs is often the cause of this failure. Another failure is due to the use of untested technologies that fail to commercially deliver on their expected promise. There are also coordination failures which are a result of fewer incentives in a market. This means that the current infrastructure is not able to deliver value, in turn producing a partnership failure (EU, 2003; 3GF, 2012).

\subsection{Critical Success Factors}

Many researchers including government funded organisations have aimed to look into the critical success factors. They have especially placed them in well-defined groups in order to further help in the research. Some of the prominent factors are described by Chan et al. (2004), Chan et al. (2009), Cheung (2009), Li et al. (2005), Oyedele (2012) and Zhang (2005). These described factors and their groups will be the focus of this particular study.

\section{Methodology}

The critical success factors that are useful in the UAE will be found using quantitative research methods. These methods will establish the PPP elements in the country which can then be used for a comparison with the UK taken as the model of best practice. A quantitative research instrument will establish the factors that will be compared. The research method employed will include the sampling process as well as the creation of the survey questionnaire. The results will be produced by carrying out a pilot study and use statistical analysis. All of these instruments will be described in this section and will note down mechanisms for the research in the UK and the UAE.

\subsection{Questionnaire Design}

The format of the interview questions was adapted from relevant sections of the template questionnaire designed by $\mathrm{Li}$ et al. (2005). The template consisted of separate segments for testing the attractive factors, value for money factors, and the critical success factors for PPP/PFI projects in the UK. The decision to adopt Li et al.'s (2005) template was based on many considerations. Firstly, this template and its contents are well recognized and cited in the PPP industry (Cheung et al. 2009; Chou and Pramudawardhani, 2015; Hwang et al., 2013; Ismail, 2013; Osei-Kyei and Chan, 2015; Robert et al., 2014). Secondly, The use of an existing source makes it easier to analyse the findings rather than using a new source of research. The template available from the research of Li et al. (2005) can be perfectly used as it is based on the UK construction industry which has similar construction codes to the UAE market.

Li et al.'s (2005) template was designed based on extensive literature review in order to establish the critical success factors for PPP/PFI in the UK, scores of studies supported each factor. For example, eight critical success factors were imported from the work of Qiao et al. (2001) in BOT projects in China. These eight factors were 'appropriate project identification', 'stable political and economic situation', 'attractive financial package', 'acceptable toll/tariff levels', 'reasonable risk allocation', 'selection of suitable subcontractors', 'management control', and 'technology transfer'. Then, these factors were crosschecked with other studies. For example, reasonable risk allocation, was supported by the work of Grant (1996) and Arthur Andersen and Enterprise LSE (2000). Another example is available financial market, which is supported by the work of Jefferies et al. (2002) and McCarthy and Tiong (1991). The same procedure was followed for the other factors. The final list of the eighteen factors were included in a questionnaire survey for a pilot study to identify their significance within the PPP/PFI projects in the UK. 
The quantitative research instrument in the form of the questionnaire was employed to find the various forms of PPP in construction projects in the UAE. The survey was aimed to establish the variation that occurs in the success factors present in a developed country such as the UK and a transitional economy, such as the UAE. The participants for the survey were carefully selected to include only those who have the experience of taking part in PPP activities in either the UK or the UAE. The responses of people without PPP experience were sampled out in the quantitative analysis. Another requirement for participants was to be working in a managerial capacity in order to receive accurate and sensitive responses against the research instrument.

The research questionnaire was performed in the two countries of the UK and the UAE. The aim was to find the particular critical success factors of PPPs by comparing the responses registered in these two different environments. Convenient sampling method was implemented, because of the difficulties faced in finding suitable candidates in the UK as there were limited references available there. Similarly, there was a small population of possible respondents in the UAE as well, as PPP related resources are hard to find. Random sampling therefore, was quite difficult to perform using ordinary methods (Ellsberg et al., 2005). Emails were dispatched to an identified group of PPP practitioners in the UAE from experts who offered mailing lists. The number of invitations sent in the UAE was 126 invitations and the returned responses were 46. About 200 generic invitations were sent with a website link to the survey to potential respondents in the UK. 141 responses were received where the qualified responses for inclusion in the analysis dropped to 62 responses, thus, the response rate was $31 \%$. In total, 92 qualified questionnaires were returned of the 326 distributed. Of these, 23 responses came from public sector 40 from the private sector and 29 from academics. The UK respondents accounted for $61.3 \%$ of the sample (Table 1). Although the number or respondent from UAE is smaller, the statistical tests showed that there is no statistical difference between the two groups. For example, the Chi square value for the UAE and the UK' samples are 114.89 and 141.70 respectively.

Table 1. Personal and job-related variables frequencies

\begin{tabular}{|c|c|c|c|c|}
\hline \multirow{2}{*}{ Variables } & \multicolumn{2}{|c|}{ UAE } & \multicolumn{2}{|c|}{ UK } \\
\hline & Freq. & $\%$ & Freq. & $\%$ \\
\hline \multicolumn{5}{|l|}{ Profession sector } \\
\hline Researcher & 3 & 10.0 & 8 & 12.9 \\
\hline Public sector practitioner & 6 & 20.0 & 17 & 27.4 \\
\hline Private sector practitioner & 21 & 70.0 & 37 & 59.7 \\
\hline \multicolumn{5}{|l|}{ Organisational level } \\
\hline Top management & 17 & 56.7 & 17 & 27.4 \\
\hline Middle management & 10 & 33.3 & 36 & 58.1 \\
\hline General staff & 3 & 10.0 & 17 & 27.4 \\
\hline \multicolumn{5}{|l|}{ Years of experience } \\
\hline Less than 6 years & 0 & 0 & 6 & 9.7 \\
\hline $6-10$ years & 7 & 23.3 & 17 & 27.4 \\
\hline $11-20$ years & 15 & 50.0 & 24 & 38.7 \\
\hline Above 21 years & 8 & 26.7 & 15 & 24.2 \\
\hline \multicolumn{5}{|l|}{ Currently involved in PPP } \\
\hline Yes & 11 & 36.7 & 44 & 71.0 \\
\hline No & 19 & 63.3 & 18 & 29.0 \\
\hline
\end{tabular}

\subsection{Pilot Study}

The questionnaire was tested on select respondents prior to sending it to the full selection of respondents in the UAE and the UK. This was necessary for checking the accuracy of items included in the scales, evaluating their relationship to the objectives of the study, taking into consideration any unaccounted for information, and making sure that the meaning was clear and no unambiguous terms could affect the responses of participants. Regarding the sample in the UAE, a pilot study was conducted with local PPP practitioners; the sample consisted of 6 participants who were all from the private sector. The UK pilot study consisted of 21 participants who were from all disciplines required in the survey: public and private practitioners and researchers. For each question, a comment box was offered so that participants could add or request any information or modifications. All of the comments were incorporated, most of which were related to using simpler terminology, as the local practitioners are relatively new to PPP practice.

\subsection{Statistical Analysis Definitions}

The technique for measuring important CSFs for PPP remains the calculation of mean scores. The mean factor values will be used to compare the presence of different 
values in the developed and emerging markets. This research technique is based on the formula described by $\mathrm{Li}$ et al. (2005) for using means in research calculations:

$$
\begin{gathered}
\text { Mean }=\frac{\sum_{i=1}^{5} i N_{i}}{\sum_{i=1}^{5} N_{i}} \\
R_{i}=\sum_{j=1}^{m} r_{i, j}
\end{gathered}
$$

$R i$ is the row sum of ranks, $r$ is rank, $i$ is country, and $j$ is rank number.

$$
R=\frac{1}{2} m(n+1)
$$

$R$ is the sum of mean values of all ranks, $\mathrm{m}$ is the number of countries, and $\mathrm{n}$ is the number of variables.

$$
S=\sum_{i=1}^{n}\left(R_{i-} R\right)^{2}
$$

$S$ is the sum of squared deviations.

$$
W=\frac{12 S}{m^{2}\left(n^{3}-1\right)}
$$

$W$ is the Kendall's coefficient of concordance.

Where $\mathrm{N}$ represents the number of respondents who replied to each 5-point Likert scale; ranging from Strongly Disagree $=1$ to Strongly Agree $=5$.

The differing group of respondents were contrasted using Kendall's Coefficient of Concordance. It is present in the SPSS statistical software program, and is ideal to find the correlation between two groups of values. KCC is shown by a W and is calculated using a formula attributed to Kendall and Smith in 1939, which is efficiently described by Tvrdon and Verner (2012). as follows:

There was also a reliability measure in order to ensure that the observed factors had better accuracy. The reliability test is designed to find if any item needs to be removed in order to achieve homogenous results among all the items using the Cronbach's alpha value (Brace et al., 2012). The alpha is a measure which is used to determine internal consistency as described by Devellis (2011):

$$
\propto=\frac{k}{k-1}\left(1-\frac{\sum \sigma_{i}^{2}}{\sigma_{y_{i}}^{2}}\right)
$$

This is where $\mathrm{k}$ is the number of items, $\sigma_{-} \mathrm{i}^{\wedge} 2$ is the sum of the variances of the individual variables, and $\sigma_{-}\left(y \_i\right)^{\wedge} 2$ is the variance of component $i$ of the current scale persons.

A factor analysis, the Varimax rotation, will be utilised to determine whether the factors are multidimensional and to check the interrelationship among all factors. Taylor (2001) offered the following linear equation for factor analysis:

$$
\begin{aligned}
& X_{n}=a_{n 1} F_{1}+a_{n 2} F_{2}+a_{n 3} F_{3}+\ldots+ \\
& a_{n m} F_{m}+a_{n} U_{n}
\end{aligned}
$$

This is where $\mathrm{X}$ is the variable, $\mathrm{F}$ is the factor, $\mathrm{U}$ is the unique factors, and $\mathrm{a}$ is the coefficient of variables in the regression equation. For the estimation of the factor scores, Taylor (2001) offered the following equation:

$$
F_{m}=b_{m 1} X_{1}+b_{m 2} X_{2}+\ldots+b_{m n} X_{n}
$$

In this equation, $\mathrm{b}$ is the factor score coefficient.

Prior to conducting the factor analysis, the respondents' data must be checked for suitability. This can be done through several tests, such as the Kaiser-MeyerOlkin (KMO) test and Bartlett's test of spherisity. KMO measures the amount of variance that can be explained by the factors within data.

Bartlett's test is used to indicate if the data is factorable. It checks for the significance of diversion of the observed correlation matrix from the identity matrix. Bartlett (1950) offered the following equation for calculating the deviation from the reference point:

$$
x^{2}=-\left(n-\frac{1}{6}(2 p+5)\right) \log _{e}|R|
$$

This is where $\mathrm{n}=\mathrm{instances}$ and $\mathrm{p}=$ variables. If Bartlett's test of spherisity is large and the significance is small $(<.05)$, it will be unlikely that the correlation is an identity matrix.

\subsection{Agreement of Participants}

The Chi square value for the UAE and the UK' samples are 114.89 and 141.70 respectively. This is significantly higher than the critical Chi square value of 27.59 when the degree of freedom is 17 . Therefore the null hypothesis that there is a significant difference in the observations is rejected, and the rankings provided by each group on the critical success factors for implementing PPPs are established to be consistent.

\subsection{Ranking of the Critical Success Factors for PPPs}

Respondents from the UAE and the UK assigned almost identical significance to the factors of this scale, as they both ranked highest the same nine factors (Table 2).

This ranking was identical for positions one, two, three, seven, eight, and nine, with a minor variation in the order of factors four, five, and six. The mean scores for the nine highest critical success factors for PPP implementation in the UAE and the UK were all above 4.00 and ranged from 4.13 to 4.70 for the UAE and from 4.05 to 4.42 for the UK. The nine factors are:

1. Commitment of public and private parties

2. Appropriate risk allocation

3. Committed and competent public agency

4. Transparent procurement process

5. Strong private consortium

6. Competitive procurement process

7. Political support

8. Detailed cost/ benefits assessment

9. Good governance 
Table 2. Mean and ranking of critical success factors for PPPs

\begin{tabular}{|c|c|c|c|c|}
\hline \multirow{2}{*}{ Factors } & \multicolumn{2}{|c|}{ UAE } & \multicolumn{2}{|c|}{ UK } \\
\hline & Mean & Rank & Mean & Rank \\
\hline Commitment of public and private parties & 4.70 & 1 & 4.42 & 1 \\
\hline Appropriate risk allocation & 4.70 & 2 & 4.40 & 2 \\
\hline Committed and competent public agency & 4.43 & 3 & 4.27 & 3 \\
\hline Transparent procurement process & 4.33 & 4 & 4.23 & 5 \\
\hline Strong private consortium & 4.33 & 5 & 4.18 & 6 \\
\hline Competitive procurement process (specs, shortlist, etc.) & 4.27 & 6 & 4.24 & 4 \\
\hline Political support & 4.23 & 7 & 4.13 & 7 \\
\hline Detailed cost/ benefits assessment & 4.17 & 8 & 4.06 & 8 \\
\hline Good governance & 4.13 & 9 & 4.05 & 9 \\
\hline Favourable legal framework & 4.00 & 10 & 3.78 & 15 \\
\hline Multi-benefit objectives of all stakeholders & 3.97 & 11 & 3.95 & 10 \\
\hline Project technical feasibility & 3.97 & 12 & 3.82 & 13 \\
\hline Shared authority between the public and private sector & 3.90 & 13 & 3.81 & 14 \\
\hline Social support & 3.83 & 14 & 3.85 & 12 \\
\hline Sound economic policy & 3.80 & 15 & 3.69 & 17 \\
\hline Government guarantees & 3.63 & 16 & 3.65 & 18 \\
\hline Macro-economic conditions & 3.53 & 17 & 3.87 & 11 \\
\hline Local financial market & 3.50 & 18 & 3.77 & 16 \\
\hline
\end{tabular}

\section{Results and Analysis}

The first step in the analysis of collected data is to ensure the reliability of the factors. The results of the reliability test for the critical success factors scale of 18 items was an inter-consistency Alpha of 0.820. There was no need to delete any items from the scale to improve Alpha.

\subsection{UAE Critical Success Factors}

All factors of the eighteen items of the critical success factors scale, produced through the utilisation of SPSS software, had correlations with other factors since they all had partial correlations above the required 0.3 with at least a single factor (Brace et al., 2012)

The value for the Kaiser-Meyer-Olkin measure of sampling adequacy was 0.541 , suggesting that the sample is factorable (Brace et al., 2012; Kaiser, 1981). Bartlett's Test of Spherisity is large (Chi-Square=296.06 and the associated significance is 0.000 ), therefore it is unlikely that the correlation is an identity matrix (Brace et al., 2012).

The data was analysed by means of principal component analysis, where factor grouping through a Varimax rotation was conducted. The eighteen items for the critical success factors scale could be regrouped into seven factors: project feasibility, effective bid management, favourable local conditions, commitment of public and private parties, government involvement, project delivery, and effective leadership.

Local financial market was the highest loading item onto the project feasibility factor of the critical success factors for implementing PPP projects. This high loading indicates the importance of having an active and efficient local financial market to support the capital outlay requirements of the project. Such capital outlay consists of debt and equity; the equity includes direct contributions by shareholders, where debt, which comes as commercial loans, bridge loans, subordinated loans, and bonds, etc., requires a mature financial market to draw from. It is therefore seen as the most critical success factor for the feasibility of the project.

Macro-economic conditions had a very high loading as well, and ranked second after local financial market onto factor one. The economic conditions of the country, such as economic growth, GDP, inflation, interest rate, and unemployment, are seen as very critical factors for the financial conditions and must be considered favourable by the public and private parties in order to ensure that PPPs will be successful projects. These favourable economic conditions will provide the stable and integrated platform where the PPP project will improve the project feasibility.

Multi-benefit objectives of stakeholders loaded high on the project feasibility factor which indicates that achieving the objectives of the private parties along with the acknowledged objectives of the public party will improve the feasibility of the project.

Project technical feasibility loaded fairly high as well on the project feasibility factor of the critical success factors. Technical feasibility is the study of the available tested technologies that are required for the delivery of the project and the technical risks that are expected to be faced by the project during its life cycle (WBI, 2012). Therefore, it is critical that technical feasibility is conducted to support the other feasibility types of the PPP project. 
Effective bid management is a very critical success factor for implementing PPP models. This factor consisted of two variables loading highly onto it: a Committed and competent public agency and a Competitive procurement process. Effective bid management requires a public agency committed to the cause of PPPs and a competent one in handling the process diligently and transparently. A competitive procurement process will ensure that the output specifications are clearly outlined, qualified tenderers are shortlisted, negotiations are effective, and the bid winner is actually the best one to deliver the objectives of the project.

The local legal framework loaded highly on the favourable local conditions, and that indicates that legal platform for agreements, policies, legislation, regulations, etc. are favourable in the view of private parties to initiate their investments in the country. Political support refers to the continuous support for the project regardless of what elections bring to the government. Social support is the public's support for the facilities and the services the PPP project is expected to bring, where the lack of their support might delay the permits for the commencement, reduce revenues due to lack of use of services, or cause political debates that might delay the project. These three items are very critical in making the local conditions favourable for private investors.

Transparent procurement process loaded very highly onto this factor. It is very critical for the PPP project, in order to succeed, to have a transparent bid process until the final close. It is very common for a PPP project to undergo a multi-stage bid process where the rights of some bidders may be infringed upon which undermines the efforts to award project to the best bidder. The government must show more commitment by ensuring transparency for the full duration of the bid process and not only in the initial submittals. The public and private parties must show equal commitment to the objectives of the PPP project in order for the project to be a successful one.

The involvement of the government by providing guarantees that safeguard the investment from certain eventualities is regarded as a critical success factor for the respondents in the UAE. This is probably attributable to the fact that the government has scarce experience in this area which might lead to failure to respond to risks in due time or to act positively in ensuring the streamline of revenues from end users. Providing a clear plan for protecting the investment will improve the chances for success and will invite more tenderers to the project. Appropriate risk allocation is another area where the government can be involved to make the PPP project more successful. Realistic risk allocation to the private party is a very critical success factor for the PPP project, which the high loading of this item indicates.

In order for the project delivery to be a smooth and successful one, a thorough and detailed cost and benefit study must be done to identify all means and alternatives that are in the best interest of all stakeholders of the PPP project. This cost/benefit study is normally part of the project appraisal stage where project feasibility, economic and commercial viability, and financing options are studied for establishing the value of using the PPP option.

Another item that loaded fairly high on the project delivery factor was strong private consortium. If the consortium of designers, contractors, and financiers under the special purpose vehicle for running the project are well established, the delivery of the project will be more successful. That will be through designing the most efficient project, being familiar with the construction and risks associated with the type of the project, and having the best financial experts in structuring the capital outlay and the management of cash flows.

Shared authority between the public and private parties is a critical factor related to effective leadership. The decision making process for the PPP project is a shared responsibility with established procedures for scope and the roles of each party. The public party should not take any measures that affect the operation of the project without prior consultation with the private party, nor should the private party make decisions affecting the predetermined objectives of the project without the consent of the public party. Sound economic policy is another important variable affecting the effective leadership of the project. This indicates that the decision makers in the government should exhibit leadership in establishing a clear and sound plan for economic growth where all sectors are integrated and viable projects are identified for the private sector to contribute its funds and experiences in their development.

\subsection{UK Critical Success Factors}

The data was analysed by means of principal component analysis, where factor grouping through a Varimax rotation was conducted. The data was analysed by means of principal component analysis, where factor grouping through a Varimax rotation was conducted (Table 3 ). The eighteen items for the critical success factors scale could be regrouped into six factors: project delivery, commitment of public and private parties, project feasibility, favourable local conditions, effective procurement, and multi-benefit objectives of all stakeholders.

Strong private consortium loaded very high on the project delivery factor. This indicates that it is a very critical success factor for the safe completion of the project. The consortium typically consists of engineering consultants, contractors, and financial institutions. The more experience and strength the team has, the more success can be expected from the PPP project. This is because there will be better capability to design the project according to the output specifications, improved control on cost and time on the project delivery by the contractor, and access to the required funds with the optimum capital outlay design and repayment structure by the financial partner.

The second item loading high on the project delivery factor was Shared authority between the public and private sectors. This variable indicates the importance of the leadership both parties should exhibit for the successful delivery of the project. There must be a mutual understanding of the importance the involvement of both parties in running the PPP project to maximise the chances for achieving the output specifications and minimise risks and their associated circumstances on the project. However, the scope of each party ensuring sharing of the leadership of the project should be clearly detailed and agreed on before the signing of the agreement to avoid any conflicts. 
A lower loading is given to transparent procurement process. This implies that transparency in the procurement process is a critical success factor for the delivery of PPP projects. The chance for the successful delivery of the project depends significantly on the bid winner. The bid winner should be the one that is established to deliver the best value for money of the project. All bidders must be involved in rigorous negotiations and must be given the information required for revising their bid proposals to advance to the next stage of the procurement process.

The last item loaded onto the project delivery factor was Political support. PPP projects are characterised by being long-term projects that span over 25 years for most cases. Political support for the projects should be durable throughout the duration of the project and not only through the legislative term. Change of politics might reduce the chances for success of the project. This can be in the form of rallying the public against the project or by creating legislation capping service charges, adding more taxes, removing any tax relief, or stopping any subsidy support.

Committed and competent public agency loaded highest onto the commitment of public and private party's factor, indicating that the public agency will increase the success rate of the project when it possesses the required authority and skills to support the project from the prequalification stage of the project all the way to the handing over of the asset. Having a committed and efficient public agency reflects the public party's commitment to the success of the project.

Commitment of Public and private parties loaded high on the second factor. Government bodies must show their commitment to the project by ensuring a smooth procurement process and an efficient management process of the development stage of the project; this can be achieved by ensuring a transparent and competitive procurement process, facilitating negotiations and renegotiations of contract terms, dealing positively with variations and eventualities, and ensuring that the conditions for the success of the project are maximised, such as the required permits, legislation, access to the project, etc. The private party, on the other hand, must appreciate all the facilities provided by the public party to complete the project successfully and must ensure the value for money objective of the project. This includes the introduction of new ideas for improved services and facilities to the public, reduction of the cost associated with project, and early completion to satisfy the end users.

The last item that loaded onto the second factor was appropriate risk allocation. Risk should be allocated to the party that is capable of dealing with its consequences best, which will lead to a more successful PPP project. This is because risk occurrences will be minimised and the cost of remedying them will be reduced as well.

Local financial market loaded highest onto the project feasibility factor for implementing PPP models. In order for the PPP project to deliver more value when compared to other conventional procurement methods, a local market for fundraising is very critical to the success of the project. It allows the private party the ability to structure the most optimal capital outlay structure that will provide more value using the full variety of funding the mature local market can offer. It also plays a significant role in the repayment of the loan and debt servicing process, where efficiency can be generated when there are more options in the local market.

Government guarantees are very critical for feasibility of the PPP projects. When the government offers guarantees to the private party by protecting the funds involved through sovereign guarantees or by guaranteeing the cash flows of the project by, for instance, signing an off-take agreement, it encourages the private party to commit more resources to the project which increases the success rate of the project. It also leads to more involvement of private sector investors into public projects, where more projects can be developed for the community and more value can be expected.

The third item that loaded onto the project feasibility factor was project technical feasibility. The study of the available tested technologies for developing the project and the technical risks that are expected to occur throughout the life cycle of the project plays a significant role in the delivery of the objectives of the PPP project. It is therefore very critical to conduct the technical feasibility study to set a direction from the early stages of the project; by doing this, the success rates of the project can be increased and the project will be more feasible.

The last item that loaded onto the project feasibility factor was Macro-economic conditions. Factors such as economic growth, GDP, inflation, interest rates, and unemployment must be in good condition to increase the success expected from the PPP project. The condition of these factors is considered critical to the feasibility of the PPP project.

A favourable legal framework had a very high loading associated with it on the favourable local conditions factor. The legal capacity for affecting the agreements, issuing policies and legislation, and resolving conflicts, among others, must be perceived as favourable by the private sector in order for them to commit resources and funds to long-term projects like PPPs.

Good governance also had a very high loading onto the favourable local conditions factor. The ability to effectively manage public affairs, to integrate with other governmental bodies, and ensure the decisions made by the government are implemented efficiently and effectively are favourable conditions for the success of the PPP project and will attract more investors into the market.

The lowest loading variable onto the favourable local conditions was sound economic policies. When the government implements economic policies where all sectors are integrated in order to produce economic growth and a systematic identification of opportunities for development is established, more confidence will be felt by the private sector to participate in such projects. It is a favourable condition that maximises participation and contributes to the success of PPP projects.

Detailed cost/benefits assessment was loaded high onto the effective bid management factor. Cost and benefit studies are very critical to the success of PPP projects, as they give an early indication of the true value of the project and whether or not it is worth pursuing this particular project over others considered for development. These studies also identify alternatives for consideration to maximise value for money. It is an integral part of the project appraisal process and complements the other studies, such as commercial and economic viability, 
project feasibility, technical feasibility, and financial appraisal.

The other variable loaded onto the effective bid management factor was Competitive procurement process. The procurement process is considered competitive and contributes to the effectiveness of the bid process when the output specifications are clearly defined where only a shortlist of best tenderers are invited, clear stages and timelines are predefined, and transparent negotiations are offered. Competitive procurement is critical to the success of PPP projects.

The multi-benefit objectives of stakeholders is a single variable factor. The objective of delivering the most effective and efficient facilities and services by the public party coupled with achieving the highest returns on the investment by the private party, along with the optimised facility and services expected by the public, must be acknowledged and worked for by all parties. The integration of objectives of all stakeholders is a very critical success factor for developing PPP projects.

\subsection{Comparison of findings from the UAE and the UK}

Regarding the critical success factors for implementing PPPs, respondents from the UAE and the UK associated almost identical significance to the factors. Both groups ranked highest the same nine factors. The mean scores for the nine highest critical success factors for PPP implementation in the UAE and the UK were all above 4.00 , making them very significant. These factors are commitment of public and private parties, appropriate risk allocation, committed and competent public agency, transparent procurement process, strong private consortium, competitive procurement process, political support, detailed cost/benefits assessment, and good governance.

The eighteen items for the critical success factors scale could be regrouped into seven groups for the UAE (project feasibility, effective bid management, favourable local conditions, commitment of public and private parties, government involvement, project delivery, and effective leadership), whereas, for the UK, they could be grouped into six groups (project delivery, commitment of public and private parties, project feasibility, favourable local conditions, effective procurement, and multi-benefit objectives of all stakeholders).

The grouping of the factors should be considered by the public party when considering the adoption of PPP models to ensure that all conditions, causal, contextual, and intervening conditions are accounted for. The critical success factors group represents the most important area that must be considered by the public party to achieve the objectives of the PPP project and how those objectives will be achieved.

\section{Conclusions}

This research aimed to identify the most significant CSFs for PPPs in in the UAE construction industry. This study endeavoured to highlight the favourable outcomes that could make PPPs superior to their conventional rivals and therefore make the decision-makers prefer them to the other procurement methods.

Through the empirical work conducted locally and in the UK, the study highlighted the most important factors to look for when deciding to develop projects through the PPP mechanism. The findings of the local surveys, when compared to the UK sample, highlighted that the local PPP practice and its surrounding conditions are almost similar to the ones in the UK, these factors are commitment of public and private parties, appropriate risk allocation, committed and competent public agency, transparent procurement process, strong private consortium, competitive procurement process, political support, detailed cost/benefits assessment, and good governance. Therefore, it could be inferred that any processes and measures that prove their success within the UK could have similar results in the UAE. There was no such detailed and empirical work for local PPP practice, and comparing it to a sample conducted in a developed country, the UK. Therefore, this outcome is expected to benefit the upper management of local government departments and the federal ministries to understand the full process for local PPPs and to help them make informed decision for what to develop as PPPs and how to develop them.

The findings were validated using the Partnering Performance Index. based on five validation interviews conducted. The CSFs ranking were validated to be comprehensive, objective, reliable, practical, replicable, and adaptable. The ranking of the CSFs developed in this research should be validated among a wider audience to establish the value of its findings and to highlight any areas for improvement. The survey used in the UAE could be repeated with a larger sample, or in another transitional economy to ensure that the findings of the small representative sample who participated in the survey are valid.

The contributions of this research to the body of knowledge can be summarised in two areas. First of all, this study contributed to research in the field of PPPs in the UAE and the UK. The comparative analysis between the two countries highlighted the similarities and differences in the practice and opened areas for future consideration. Second, this study reused a survey template conducted in the UK in 2003 and re-examined a large sample. Such results highlighted the progression in the UK PPP practice, which was significant, and opens areas for detailed research on such progression. 
Table 3. UK Critical success factors- Rotated Component Matrix

\begin{tabular}{|c|c|c|c|c|c|c|}
\hline \multirow{2}{*}{ Factors } & \multicolumn{6}{|c|}{ Component } \\
\hline & 1 & 2 & 3 & 4 & 5 & 6 \\
\hline Strong private consortium & .851 & & & & & \\
\hline Shared authority & .742 & & & & & \\
\hline Transparent procurement process & .665 & & & & & \\
\hline Political support & .514 & & & & & \\
\hline Committed and competent public agency & & .864 & & & & \\
\hline Commitment of public and private parties & & .763 & & & & \\
\hline Appropriate risk allocation & & .540 & & & & \\
\hline \multicolumn{7}{|l|}{ Social support } \\
\hline Local financial market & & & .807 & & & \\
\hline Government guarantees & & & .620 & & & .553 \\
\hline Project technical feasibility & & & .603 & & & \\
\hline Macro-economic conditions & & & .539 & & & \\
\hline Favourable legal framework & & & & .847 & & \\
\hline Good governance & & & & .808 & & \\
\hline Sound economic policy & & & .526 & .527 & & \\
\hline Detailed cost/ benefits assessment & & & & & .839 & \\
\hline Competitive procurement process (specs, shortlist, etc.) & & & & & .548 & \\
\hline Multi-benefit objectives of all stakeholders & & & & & & .807 \\
\hline
\end{tabular}

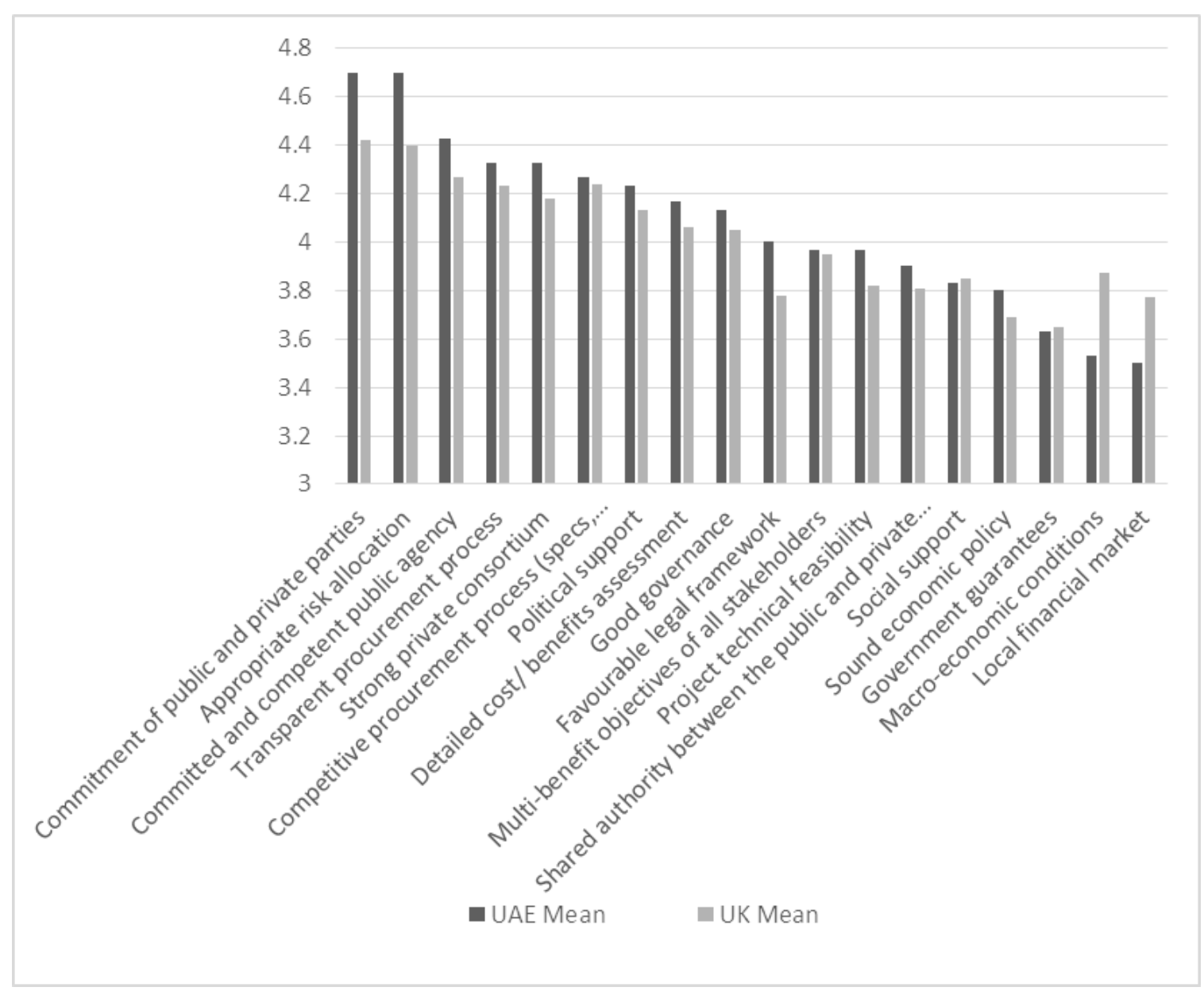

Fig. 1. Comparison of CSFs findings from the UAE and the UK 


\section{References}

3GF-The Global Green Growth Forum. (2012). Accelerating Green Growth Through Public-Private Partnerships. [Online]. [Accessed 2 November 2016]. Available http://3gf.dk/en/ /media/3gf/Documents/Analytical tools/3GF Report Accelerating Green Growth Through Public-Private Partnerships.pdf

Alfen, H. (2010). Public Private Partnership (PPP) as part of Infrastructure Management solutions- a structural approach of delimiting PPP from other Private Sector participation Models. 18th CIB World Building Congress, May 2010 Salford, United Kingdom. [Online]. [Accessed 2 November 2016]. Available at: http://www.irbnet.de/daten/iconda/CIB_DC24060.pdf \#page $=18$

Almarri, K. and Blackwell, P. (2014). Improving risk sharing and investment appraisal for PPP procurement success in large green projects. Procedia-Social and Behavioral Sciences, 119, 847-856.

Bartlett, M. (1950). Tests of significance in factor analysis. British Journal of statistical psychology, 3(2), 77-85.

Brace, N., Kemp, R., and Snelgar, R. (2012). SPSS for psychologist. New York: MacMillan.

Broadbent, J. and Laughlin, R. (2003). Public private partnerships: an introduction. Accounting, Auditing \& Accountability Journal, 16(3), 332-341.

Broadbent, J. and Laughlin, R. (2004). PPPs: Nnature, development and unanswered questions. Australian Accounting Review, 14(33), 4-10.

Chan, A., Chan, D., Chiang, Y., Tang, B., Chan, E., and Ho, K. (2004). Exploring critical success factors for partnering in construction projects. Journal of Construction Engineering and Management, 130(2), 188-198.

Chan, A., Lam, P., Chan, D., Cheung, E., and Ke, Y. (2009). Potential obstacles to successful implementation of public-private partnerships in Beijing and the Hong Kong special administrative region. Journal of Management in Engineering, 26(1), $30-40$.

Cheung, E. (2009). Developing a best practice framework for implementing public private partnerships $(P P P)$ in Hong Kong. Ph.D. Thesis. Queensland University of Technology. [Online]. [Accessed 16 July 2016]. Available http://core.ac.uk/download/pdf/10894601.pdf

Chou, J. S., Tserng, H. P., Lin, C., and Yeh, C. P. (2012). Critical factors and risk allocation for PPP policy: Comparison between HSR and general infrastructure projects. Transport Policy, 22, 36-48.

Chou, J. and Pramudawardhani, D. (2015). Cross-country comparisons of key drivers, critical success factors and risk allocation for public-private partnership projects. International Journal of Project Management, 33(5), 1136-1150.

Dada, M. O. (2012). Analysis of conflict centers in projects procured with traditional and integrated methods in Nigeria. Journal of Engineering, Project, and Production Management, 2(2), 66.

DeVellis, R. (2011). Scale development: Theory and applications (Vol. 26). Thousand Oaks: Sage Publications.

Dulaimi, F., Alhashemi, M., Ling, Y., and Kumaraswamy, M. (2010). The execution of public-private partnership projects in the UAE. Construction Management and Economics, 28(4), 393-402.

Ellsberg, M., Heise, L., Watts, C., and Garcia-Moreno, C. (2005). Researching Violence Against Women: A Practical Guide for Researchers and Activists. World Health Organization, PATH: Washington DC. [Online]. [Accessed 2 November 2016]]. Available at: http://cdrwww.who.int/gender/violence/who_multicou ntry_study/Introduction-Chapter1-Chapter2.pdf

EU-European Commission. (2003). Guidelines for successful public- private partnerships. DirectorateGeneral Regional Policy, Directorate General for Research. Brussels. [Online]. [Accessed 2 November 2016]. Available

at: http://ec.europa.eu/regional_policy/sources/docgener/ guides/ppp_en.pdf

Grant, T. (1996). Keys to successful public-private partnerships. Canadian Business Review, 23, 27-28.

HMT-Her Majesty's Treasury (2014). Private Finance Initiative projects: 2014 summary data. [Online]. [Accessed 2 November 2016]. Available at: https://www.gov.uk/government/uploads/system/uplo ads/attachment_data/file/387228/pfi_projects_2014_s ummary_data_final_15122014.pdf

Hoppe, E. and Schmitz, P. (2013). Public-private partnerships versus traditional procurement: Innovation incentives and information gathering. The RAND Journal of Economics, 44(1), 56-74.

Hwang, B., Zhao, X., and Gay, M. (2013). Public private partnership projects in Singapore: Factors, critical risks and preferred risk allocation from the perspective of contractors. International Journal of Project Management, 31(3), 424-433.

Ismail, S. (2013). Critical success factors of public private partnership (PPP) implementation in Malaysia. AsiaPacific Journal of Business Administration, 5(1), 6-19.

Jefferies, M., Gameson, R., and Rowlinson, S. (2002). Critical success factors of the BOOT procurement system: reflections from the Stadium Australia case study. Engineering Construction and Architectural Management, 9(4), 352-361.

Kaiser, H. (1981). A revised measure of sampling adequacy for factor-analytic data matrices. Educational and Psychological Measurement. [Online]. [Accessed 2 November 2016]. Available at: http://psycnet.apa.org/psycinfo/1981-27124-001

Li, B., Akintoye, A., Edwards, P. J., and Hardcastle, C. (2005). Critical success factors for PPP/PFI projects in the UK construction industry. Construction Management and Economics, 23(5), 459-471.

McCarthy, S. C. and Tiong, R. L. (1991). Financial and contractual aspects of build-operate-transfer projects. International Journal of Project Management, 9(4), 222-227.

Michael H. (2016). Rise in public-private partnerships in UAE. The National.

NSW-The Treasury of the New South Wales Government. (2012). Policy and Guidelines for PPPs. [Online]. [Accessed 2 November 2016]. Available at: http://www.treasury.nsw.gov.au/_data/assets/pdf_file /0015/22605/NSW_PPP_Guidelines_2012_Final_Ver sion_14_August_2012_dnd.pdf

Osei-Kyei, R. and Chan, A. (2015). Review of studies on the Critical Success Factors for Public-Private Partnership (PPP) projects from 1990 to 2013. International Journal of Project Management, 33(6), 1335-1346. 
Oyedele, L. (2012). Avoiding performance failure payment deductions in PFI/PPP projects: model of critical success factors. Journal of Performance of Constructed Facilities, 27(3), 283-294.

Parker, D. (2009). Editorial: PPP/PFI-Solution or Problem?. Economic Affairs, 29(1), 2-6.

PPPC-The Canadian council for PPP (2011). PublicPrivate Partnerships: A guide for municipalities. [Online]. [Accessed 2 November 2016]. Available at: http://www.p3canada.ca/ /media/english/resourceslibrary/files/p3\%20guide\%20for\%20municipalities.pd $\mathrm{f}$

Qiao, L., Wang, S. Q., Tiong, R. L., and Chan, T. S. (2001). Framework for critical success factors of BOT projects in China. The Journal of Structured Finance, 7(1), 53-61.

Robert, O., Dansoh, A., and Ofori-Kuragu, J. (2014). Reasons for adopting Public-Private Partnership (PPP) for construction projects in Ghana. International Journal of Construction Management, 14(4), 227-238.

UOM-The University of Melbourne, Australia. (2012). Public Private Partnerships. [Online]. [Accessed 2 November 2016]. Available at: http://www.csdila.unimelb.edu.au/sis/Public_Policy_T heories/PPP.html

Verner, T. and Tvrdon, M. (2012). Comparison of National Competitiveness: Non-parametrical Approach. In International Conference on Economics, Business and Management (ICEBM), 62-66. [Online]. [Accessed 2 November 2016]. Available at: http://www.ipedr.com/vol55/012-ICEBM2012K00027.pdf

WBI-The World Bank. (2012). Public-Private Partnerships, Reference Guide Version 1.0. [Online]. [Accessed 2 November 2016]. Available at: https://openknowledge.worldbank.org/handle/10986/1 6055

Yang, Y., Hou, Y., and Wang, Y. (2013). On the development of public-private partnerships in transitional economies: An explanatory framework. Public Administration Review, 73(2), 301-310.

Yeung, J., Chan, A., Chan, D., and Li, L. (2007). Development of a partnering performance index (PPI) for construction projects in Hong Kong: a Delphi study. Construction Management and Economics, 25(12), 1219-1237.

Zhang, X. (2005). Critical success factors for publicprivate partnerships in infrastructure development. Journal of Construction Engineering and Management, 131(1), 3-14.

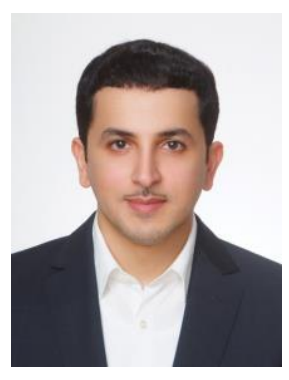

Dr. Khalid is an assistant professor of project management at the Engineering and IT department of the British university in Dubai. Dr. Khalid is proclaimed for setting high standard of accomplishment by holding the first $\mathrm{PhD}$ award in Project Management in the region. Dr. Khalid has an undergraduate degree in Civil Engineering from the University of Arizona and master's degree in Engineering Management from the Catholic University of America. Following which he commenced his engineering career in 1996 in the Dubai Municipality and has been in the government services in the Sewerage \&
Irrigation Department and the Roads Department as Head in the Roads Construction Section.

Dr. Khalid holds the credential of having produced, through a doctoral program, the first framework for developing projects through public private partnerships (PPP) in the UAE. This framework is the first to lay the foundations for a standardized PPP practice in the UAE for practitioners. It highlights the most important factors for the success of PPP projects, such as value for money, risk sharing and allocation, renegotiations, and the roles of the public and private parties.

Dr. Khalid is also credited for developing a framework for establishing a nuclear research reactor project in the UAE through the utilization of public private partnerships, which was one of the first frameworks for PPPs in research reactor projects in the world and followed strict safeguards and required full awareness of nuclear safety, security \& control of nuclear materials handling.

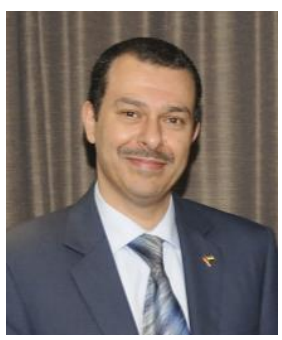

Prof. Bassam Abu-Hijleh is currently the Dean of Faculty of Engineering \& IT (since Sept. 2010) as well as the Atkins Chair of the MSc and PhD Sustainable programmes (since Sept. 2006) at the British University in Dubai (BUiD). He holds a $\mathrm{PhD}$ in Mechanical Engineering from the Ohio State University-USA. With $25+$ years' post-PhD experience in energy related academia and research Prof. Abu-Hijleh have a strong technical background in Energy related topics with special focus on Renewable Energy and Energy Management \& Conservation. His current research interests focuses on Experimental and simulation study of solar energy, Renewable/alternative energy sources, advanced energy production practices and Energy conservation \& management. He published more than 110 papers in international journals and conferences. $\mathrm{He}$ holds LEED AP, CEM and SEM professional certification. 